NBER WORKING PAPER SERIES

INSTRUMENTS OF COMMERCE AND KNOWLEDGE:

PROBE MICROSCOPY, 1980-2000

\author{
Cyrus C. M. Mody \\ Working Paper 12700 \\ http://www.nber.org/papers/w12700 \\ NATIONAL BUREAU OF ECONOMIC RESEARCH \\ 1050 Massachusetts Avenue \\ Cambridge, MA 02138 \\ November 2006
}

The author thanks Mike Lynch, Arthur Daemmrich, Steve Shapin, Phil Scranton, and John Staudenmaier for their advice and encouragement on various drafts of this paper. Audiences at Arizona State, the American Sociological Association, and the Chemical Heritage Foundation also provided useful comments. This work was made possible by funding from the National Science Foundation, the IEEE History Center, and the National Bureau of Economic Research, as well as by the generous cooperation of my interviewees. The views expressed herein are those of the author(s) and do not necessarily reflect the views of the National Bureau of Economic Research.

(C) 2006 by Cyrus C. M. Mody. All rights reserved. Short sections of text, not to exceed two paragraphs, may be quoted without explicit permission provided that full credit, including $\odot$ notice, is given to the source. 
Instruments of Commerce and Knowledge: Probe Microscopy, 1980-2000

Cyrus C. M. Mody

NBER Working Paper No. 12700

November 2006

JEL No. N8,O17,O3,O31,O33,Z1,Z13

\begin{abstract}
Longstanding debates about the role of the university in national culture and the global economy have entered a new phase in the past decade in most industrialized, and several industrializing, countries. One important focus of this debate is corporate involvement in academic scientific research. Proponents of the academic capitalism say that corporate involvement makes the university leaner, more agile, better able to respond to the needs of the day. Critics say that corporate involvement leaves society without the independent, critical voices traditionally lodged in universities. I argue that a science and technology studies perspective, using case studies of research communities, can push this debate in directions envisioned by neither proponents nor critics. I use the development and commercialization of the scanning tunneling microscope and the atomic force microscope as an example of how research communities continually redraw the line between corporate and academic institutions.
\end{abstract}

Cyrus C. M. Mody

Center for Contemporary History and Policy

Chemical Heritage Foundation

315 Chestnut St.

Philadelphia, PA 19106

cmody@chemheritage.org 


\title{
Instruments of Commerce and Knowledge: Probe Microscopy, 1980-2000
}

\author{
Cyrus C. M. Mody \\ Chemical Heritage Foundation
}

\section{Introduction}

The voices of editorialists and analysts excoriating or praising commercialization of products of higher education has recently grown very loud. ${ }^{1}$ Yet this debate too often proceeds at an abstract level divorced from the small-scale settings where commercialization actually occurs. The questions asked are too stark, and the dangers and benefits of academic entrepreneurialism are amplified beyond recognition. As Steven Shapin notes in a recent survey, proponents’ and nay-sayers’ limited historical horizons lead to, among other things, ludicrous over-praising of incentives to patent academic research and over-dire warnings about the corporate university. ${ }^{2}$ The few historical studies that could contribute to this debate, while praiseworthy, have

\footnotetext{
My thanks to Mike Lynch, Arthur Daemmrich, Steve Shapin, John Staudenmaier, and David Kaiser for their advice and encouragement on various drafts of this paper. Audiences at Arizona State, the American Sociological Association, the National Bureau of Economic Research, and the Chemical Heritage Foundation also provided useful comments. Portions of this work have appeared in Technology and Culture. This work was made possible by funding from NBER, the NSF, and the IEEE History Center, as well as by the generous cooperation of my interviewees.

${ }^{1}$ See Norman E. Bowie, ed., University-Business Partnerships: An Assessment, Issues in Academic Ethics (Lanham, MD: Rowman \& Littlefield, 1994); Derek Bok, Universities in the Marketplace: The Commercialization of Higher Education (Princeton: Princeton University Press, 2003); Roger L. Geiger, Knowledge and Money: Research Universities and the Paradox of the Marketplace (Stanford: Stanford University Press, 2004); Frank Newman, Lara Couturier, and Jamie Scurry, The Future of Higher Education: Rhetoric, Reality, and the Risks of the Market (San Francisco: Jossey-Bass, 2004); David L. Kirp, Shakespeare, Einstein, and the Bottom Line: The Marketing of Higher Education (Cambridge, MA: Harvard University Press, 2003); Eric Gould, The University in a Corporate Culture (New Haven: Yale University Press, 2003); and the essays in Donald G. Stein, ed., Buying In Or Selling Out: The Commercialization of the American Research University (New Brunswick: Rutgers University Press, 2004) and Joseph C. Burke, ed., Achieving Accountability in Higher Education: Balancing Public, Academic, and Market Demands (San Francisco: Jossey-Bass, 2004).

2 Steven Shapin, “Ivory Trade,” London Review of Books 25, no. 17 (2003): 15-19.
} 
concentrated too narrowly on a handful of particularly entrepreneurial universities

(Stanford and MIT), disciplines/industries (microelectronics and biotechnology), and

regions (Silicon Valley and Route 128 near Boston). ${ }^{3}$

Yet these studies neglect important aspects of participants’ experience of corporate-academic cooperation. Most researchers participate in networks that are geographically dispersed and that include colleagues in both academia and industry and from a variety of disciplines. To understand the commercialization of academic knowledge, we need a multi-institutional, multi-disciplinary, multi-regional unit of analysis - what I will call an "instrumental community.” By this I mean the porous group of people commonly oriented to building, developing, using, selling, and popularizing a particular technology of measurement. ${ }^{4}$ Such communities are “instrumental” primarily in focusing on new research tools - microscopes, fruit flies,

\footnotetext{
${ }^{3}$ For MIT and Stanford, see Stuart W. Leslie, The Cold War and American Science: The MilitaryIndustrial-Academic Complex at MIT and Stanford, 1 ed. (New York, NY: Columbia University Press, 1993); John Servos, “The industrial relations of science: Chemical engineering at MIT, 1900-1939,” Isis 81 (1980): 531-49; R. S. Lowen, "Transforming the University - Administrators, Physicists, and Industrial and Federal Patronage At Stanford, 1935-49," History of Education Quarterly 31, no. 3 (1991): 365-388; and C. Lecuyer, "Academic science and technology in the service of industry: MIT creates a "permeable" engineering school," American Economic Review 88, no. 2 (1998): 28-33. For biotech and microelectronics, see Martin Kenney, Biotechnology: The University-Industrial Complex (New Haven: Yale University Press, 1986) and Christophe Lécuyer, Making Silicon Valley: Innovation and the Growth of High Tech, 1930-1970 (Cambridge, Mass., 2006). For a regional perspective, see Anna-Lee Saxenian, Regional Networks: Industrial Adaptation in Silicon Valley and Route 128 (Cambridge, MA: Harvard University Press, 1993); Peter Hall and Ann Markusen, eds., Silicon Landscapes (Boston: Allen \& Unwin, 1985).

${ }^{4}$ The "instrumental community" bears a close resemblance to the "innovation communities" analyzed by Sonali K. Shah, “Open Beyond Software," in Open Sources 2.0: The Continuing Evolution, ed. Danese Cooper, Chris DiBona, and Mark Stone (Sebastopol, CA: O’Reilly Media, 2005). “Instrumental community" is - so far as I know - my own formulation, but others have covered very similar ground, especially: Stuart Blume, Insight and Industry: On the Dynamics of Technological Change in Medicine (Cambridge, MA: MIT Press, 1992) and Terry Shinn, "Crossing Boundaries: The Emergence of ResearchTechnology Communities," in Universities and the Global Knowledge Economy: A Triple Helix of University-Industry-Government Relations, ed. Henry Etzkowitz and Loet Leydesdorff (London: Pinter, 1997), 85-96.
} 
tobacco mosaic virus, lab rats, cathode ray tubes, etc. ${ }^{5}$ Because such communities

usually include academic and commercial participants, though, they will often seek ways to morph those tools into industrially-relevant devices. Thus, such communities are also “instrumental” in focusing on new ways of doing or making things.

There are a number of excellent case studies of various instrumental communities, spanning from the seventeenth century to the 1960 s. ${ }^{6}$ Yet there have been virtually no studies of instrumental communities that have arisen since the late 1970s. This is unfortunate in that this is the period on which the most overheated rhetoric about academic capitalism is focused. We know that there have been significant changes in legislation, federal funding, corporate research, and the demographics of science in the past three decades. ${ }^{7}$ We do not know how those changes have affected the operation of instrumental communities, nor how they have affected relationships between corporate and academic members of those communities. This chapter aims to bring these issues to the fore through a case study of the development and commercialization of the scanning tunneling microscope (STM) and its near-relatives, the atomic force microscope (AFM)

\footnotetext{
${ }^{5}$ For studies in this vein, see: Robert Kohler, Lords of the Fly (Chicago: University of Chicago Press, 1994), Boelie Elzen, "Two Ultracentrifuges: A Comparative Study of the Social Construction of Artefacts," Social Studies of Science 16 (1986): 621-662; Karen Rader, Making Mice: Standardizing Animals for American Biomedical Research, 1900-1955 (Princeton: Princeton University Press, 2004).

${ }^{6}$ See, chronologically, Steven Shapin and Simon Schaffer, Leviathan and the Air-Pump: Hobbes, Boyle, and the Experimental Life (Princeton: Princeton University Press, 1985); Myles W. Jackson, "Buying the dark lines of the spectrum: Joseph von Fraunhofer's standard for the manufacture of optical glass," in Scientific Credibility and Technical Standards in $19^{\text {th }}$ and Early $20^{\text {th }}$ Century Germany and Britain, Jed Z. Buchwald, ed. (Dordrecht: Kluwer Academic, 1996), 1-22; and David Pantalony, "Seeing a voice: Rudolph Koenig's instruments for studying vowel sounds," American Journal of Psychology 117, no. 3 (2004): 425442; Nicolas Rasmussen, Picture Control: The Electron Microscope and the Transformation of Biology in America, 1940-1960 (Stanford: Stanford University Press, 1997); Joan Lisa Bromberg, The Laser in America, 1950-1970 (Cambridge, MA: Massachusetts Institute of Technology Press, 1991); and Timothy Lenoir and Christoph Lécuyer, "Instrument Makers and Discipline Builders: The Case of Nuclear Magnetic Resonance,” Perspectives on Science, no. 3 (1995): 276-345.

${ }^{7}$ As outlined in Philip Mirowski and Esther-Miriam Sent, "STS, the Economics of Science, and the Commercialization of University Science,” ed. Edward Hackett, Olga Amsterdamska, Michael Lynch, and Judy Wacjman (Cambridge, MA: MIT Press, forthcoming).
} 
and magnetic force microscope (MFM) - known collectively as probe microscopes. ${ }^{8}$

Twenty-five years ago there was one, home-made, unreliable STM at the IBM research

lab in Zurich. Today, through the joint efforts of corporate and academic researchers,

there are thousands of AFMs, MFMs, and STMs at universities, national labs, and

industrial research and quality control facilities. High school students make STMs from

Legos, while chip manufacturers use million-dollar AFMs on the factory floor. One

AFM has even made it to the surface of Mars.

\section{Inventing and Community-Building}

Invention can be a precarious business, particularly for corporate scientists and

engineers. ${ }^{9}$ Inventions often emerge from digressions from assigned tasks, and may not

initially meet any commercial objective. The STM, for one, was this kind of institutional

orphan. Its inventors, Gerd Binnig and Heini Rohrer, had been tasked with finding new

\footnotetext{
${ }^{8}$ The technical details of the microscopes are important to this story, but can be glossed for the purposes of this chapter. Basically, all scanning probe microscopes bring a very small solid probe very close (usually to within a nanometer - one billionth of a meter) to a sample and measure the strength of different kinds of interactions between probe and sample to determine the height (and other characteristics) of the sample. The probe is then rastered much like the pixels on a TV screen and a matrix of values for the strength of the tip-sample interaction is converted into a visual "picture" of the surface. Different probe microscopes use different kinds of tip-sample interactions to generate their images. The first, the STM, works by putting a voltage difference between the tip and a metal or semiconductor sample; when the tip is brought close to the sample, some electrons will quantum mechanically "tunnel" between them. The number of electrons that do so (the "tunnel current") is exponentially dependent on the distance between tip and sample; also, the stream of tunneling electrons is very narrow. Thus, an STM has ultrahigh resolution both vertically and laterally - most STMs can actually see individual atoms on many samples. Today, the STM's younger cousin, the atomic force microscope, is more commonly used. An AFM uses a very small but flexible cantilever as a probe; as the tip of the cantilever (usually weighted with a small pyramid of extra atoms) is brought close to the surface, the cantilever bends due to the attraction or repulsion of interatomic forces between tip and sample. The degree of bending is then a proxy for the height of the surface. Originally this bending was measured by putting an STM on the back of the cantilever; today the deflection is detected by bouncing a laser off the cantilever and measuring the movement of the reflected spot. Another common and industrially-relevant tool, the magnetic force microscope, works in a similar way, but uses a magnetic tip to map the strength of magnetic domains on a surface, rather than surface height. Both the AFM and MFM have slightly less resolution than the STM (i.e. they cannot usually see single atoms); yet because they (unlike the STM) can be used on insulators as well as conductors, and in air and fluids as well as vacuum, they have become much more popular.

${ }^{9}$ Indeed, inventors of instruments (or those who take credit for having invented them) often seem to have vexed positions within the firms that employ them. See, for instance, the description of Kary Mullis' antagonistic relationship with Cetus in Paul Rabinow, Making PCR: A Story of Biotechnology (Chicago: University of Chicago Press, 1996).
} 
ways to characterize thin films used in an advanced supercomputer project on which IBM had staked much of its reputation. Yet by the time they came up with the STM as an answer to the thin film problem, the supercomputer project had been canceled. ${ }^{10}$ Binnig and Rohrer's response was three-fold. First, they hid the STM from managerial view easy enough at the Zurich lab, far from corporate headquarters and well-known for lax oversight. Second, they began querying IBM colleagues about new ways to use the STM, eventually attracting interest from the company's large cadre of semiconductor surface scientists.

Their third, key strategy was to cultivate an extramural, academic community committed to the STM by encouraging their network of acquaintances to replicate the instrument. As this instrumental community grew both inside and outside Big Blue, IBM's senior research managers decided that the STM - despite the absence of commercial relevance - should become a major corporate project. Multiple groups of scientists at the IBM laboratories in Zurich, Yorktown Heights, New York and Almaden, California were recruited out of graduate school to build STMs and make discoveries that would bring credit to the instrument and to the company. In turn, IBM's research archrival, Bell Labs, saw a need to steal Big Blue’s thunder and began recruiting its own cadre of STMers.

The dynamics of building the STM community show how the corporate and academic worlds are interpermeated much more thoroughly and enduringly than is often noticed in debates about academic commercialization. Binnig and Rohrer could quickly cultivate a set of academic STM replicators because of networks of personnel exchange

\footnotetext{
${ }^{10}$ G. Binnig and H. Rohrer, “The Scanning Tunneling Microscope,” Scientific American 253, no. 2 (1985): 50-6 and G. Binnig and H. Rohrer, "Scanning Tunneling Microscopy - From Birth to Adolescence," Reviews of Modern Physics 59, no. 3 (1987): 615-625.
} 
between IBM and various universities - some replicators were professors taking

sabbaticals in Zurich, some were academics Rohrer had known from his own sabbaticals

at universities, and some were people who had been postdocs at IBM or currently had

students serving postdoctoral appointments there. ${ }^{11}$

Similarly, interest in the STM grew within IBM and Bell Labs not because it could solve commercially-relevant problems, but because it could generate credible knowledge within academic disciplines such as physics and surface science. ${ }^{12}$ Accolades from an academic audience - evidenced by standing-room-only crowds at American Physical Society meetings, awarding of the Nobel Prize to Binnig and Rohrer in 1986, and the growth of academic STM - were largely the aim of IBM’s STM program. Moreover, prestige within a hot, new instrumental community like STM in turn allowed IBM to recruit the best graduate students as postdocs and junior researchers - exactly the people who built the second and third generations of IBM's tunneling microscopes. Today, some of those same people have returned IBM’s investment by becoming the leading figures in nanotechnology research - securing Big Blue’s reputation and intellectual property in what is, at last, a commercially important area.

\section{Dynamics of Community}

\footnotetext{
11 The source material for this study is a collection of interviews with $150+$ probe microscopists conducted between 2000 and 2004. I will reference specific oral histories using an alphanumeric code listed in the appendix to this article. Information about the corporate-academic network of sabbaticals and hires came from, among others, $<\mathrm{TB} 1>$, $<\mathrm{JM} 1>$, and $<\mathrm{PH} 1>$.

12 There is rich historical material on the large, corporate labs of the twentieth century: George Wise, Willis R. Whitney, General Electric, and the Origins of U.S. Industrial Research (New York: Columbia University Press, 1985); Michael Riordan and Lillian Hoddeson, Crystal Fire: The Birth of the Information Age (New York: Norton, 1997); Lillian Hartmann Hoddeson, "The roots of solid-state research at Bell Labs,” Physics Today (1977); Leonard Reich, The Making of American Industrial Research: Science and Business at GE and Bell, 1876-1926 (Cambridge, UK: Cambridge University Press, 1985). Most relevant here are analyses of the tenuous relationship between research and production at IBM: Ross Knox Bassett, To the Digital Age: Research Labs, Start-Up Companies, and the Rise of MOS Technology (Baltimore: Johns Hopkins, 2002); Scott Knowles and Stuart W. Leslie, “'Industrial Versailles' - Eero Saarinen's Corporate Campuses for GM, IBM, and AT\&T,” Isis 92: 1-33.
} 
By 1986, then, the STM was no longer a precarious technology. Crucially, the instrumental community beginning to take shape was dominated by corporate groups, especially from IBM and Bell Labs. Early academic STMers, such as Paul Hansma at the University of California at Santa Barbara (UCSB), Calvin Quate at Stanford, and John Baldeschwieler at Caltech, were important contributors to the community; yet these academics struggled to compete with corporate groups that were better-resourced and (more importantly) were working alongside (or in competition with) numerous other STMers in the same building. The tacit knowledge needed to build an STM flowed more quickly at IBM and Bell Labs, allowing those organizations to rapidly expand their commitment to STM. ${ }^{13}$

This meant the questions most important to the early STM community were those of relevance to groups at IBM and Bell Labs. In particular, since Binnig and Rohrer had been most successful in enrolling colleagues interested in the surface structure of metals and semiconductors, those the community's chosen materials. Indeed, a few surfaces (especially of silicon) served as yardsticks for measuring whether a group had a working STM or not - until a group’s STM had resolved single atoms of silicon, its builders could not enter the top tier of STM builders. ${ }^{14}$ Other metal and semiconductor surfaces served as milestones, with different groups racing each other to be the first to achieve atomic resolution. Thus, interest in semiconductors - obviously strong at IBM and Bell Labs -

\footnotetext{
${ }^{13}$ For treatments of the concept of tacit knowledge, especially as applied to instrument-building, see H. M. Collins, "The Seven Sexes: A Study in the Sociology of a Phenomenon, or the Replication of Experiments in Physics," Sociology 9, no. 2 (May) (1975): 205-224; Harry Collins, “Tacit Knowledge, Trust, and the Q of Sapphire," Social Studies of Science 31, no. 1 (2001): 71-86; and Michael Polanyi, Personal Knowledge: Towards a Post-Critical Philosophy (New York: Harper Torchbooks, 1962).

${ }^{14}<\mathrm{JD} 2>$, $<\mathrm{PW} 2>$.
} 
helped standardize activity in the community and allowed participants to judge each other's progress.

Initially, academics such as Quate and Baldeschwieler tried to keep up in these races. Notably, Quate, located near both Silicon Valley and a cadre of former students and postdocs at IBM Almaden, had the most success in this area. Yet even he struggled to develop familiarity in handling metals and semiconductors among his students and in making his results credible to corporate STMers. ${ }^{15}$ Hansma, meanwhile, saw that IBM and Bell Labs would continue to dominate the study of metal and semiconductor surfaces and began carving alternative niches. ${ }^{16}$ Soon, Quate, Baldeschwieler, and other academics followed suit, so that the STM community began to segregate into two moieties - surface science STMers, dominated by (but not exclusive to) corporate and national laboratories on the East Coast; and non-surface scientists, dominated by (but not exclusive to) universities on the West Coast. ${ }^{17}$

These two moieties continued to share a great deal. Members of each occasionally collaborated, and a few people moved from one to the other. More importantly, the basic design of the STM was - at this stage - common to both, so design innovations in one moiety could be transported to the other. This meant that opportunities for co-presence - conferences and visits and sabbaticals between labs continued to be useful. Yet in a number of areas the two moieties established starkly different styles. In particular, corporate STMers, coming out of a surface science

\footnotetext{
$15<$ JD2 $>$.

${ }^{16}<\mathrm{PH} 1>$, $<\mathrm{BD} 2>$.

${ }^{17}$ Crucial members of the latter, predominantly academic, moiety were Quate's allies within IBM: Dan Rugar, John Foster, and Tom Albrecht (former students who worked at IBM Almaden); Kumar Wickramasinghe (a former postdoc, later at IBM Yorktown); and Gerd Binnig (who took a sabbatical at Stanford in 1985-6).
} 
tradition that valued ultraclean samples and rigid control of conditions, built their STMs for compatibility with ultrahigh vacuum (UHV) chambers. These chambers were large, finicky, expensive, and time-consuming, so academic STMers developed alternatives such as STM in air, in water, in oil, and in a variety of gases. ${ }^{18}$

Freed from the constraints of UHV and the need to please surface scientists, academic STMers moved to a radically open-ended, sometimes chaotic mode of experimentation. They saw that corporate surface science STM had succeeded by appealing to specific disciplinary audiences and by orienting to a few yardstick materials by which members of the community could be measured, and sought out new audiences and yardstick materials of their own. It was unclear, though, which audiences might accept the STM, and how the STM should be adapted to achieve acceptance. Thus, academics like Quate and Hansma encouraged their students to quickly build a wide variety of microscopes and to playfully use them to characterize haphazard materials leaves of houseplants, polaroids, bone from ribeye steaks, ice, the electrochemistry of Coke versus Pepsi, etc. ${ }^{19}$ This bricolage fit well with these groups’ shoestring operation (in contrast to the corporate groups) and extended even into microscope-building: the Baldeschwieler group made STM probes from pencil leads, for instance, while the Hansma group made AFM tips from hand-crushed pawn shop diamonds, glued to tin foil cantilevers with brushes made from their own eyebrow hairs.

Yet such indiscipline could damage STM’s acceptance by new disciplinary audiences, since the microscope-builders did not know how to prepare samples and interpret images in ways that would be credible to, for example, biologists,

\footnotetext{
$18<\mathrm{CP} 1>,<\mathrm{PH} 1>$.

$19<\mathrm{CP} 1>$, $<$ JN1 $>$.
} 
electrochemists, or materials scientists. Thus, Quate, Hansma, and other academic STMers began bringing representatives (postdocs or young professors) from potential new disciplinary audiences in to work with their students, learn how to use the microscope, show the group how to prepare samples, and then proselytize for the technique within their home community. Often, these people took a microscope with them when they left, or founded their own microscope-building group, and used their knowledge of probe microscopy as a tool for gaining prestige among disciplinary colleagues and securing tenure from their universities. ${ }^{20}$

Thus, the differences between the two moieties were as much about pedagogy and career arc as they were about samples, designs, and audience. In groups such as Quate’s and Hansma's (mirrored, in part, by their collaborators' groups), graduate students were trained to build instruments quickly and collaboratively, to think primarily about novel design rather than use; postdocs, meanwhile, were trained to develop new uses out of those designs, and to integrate a new technology into an established discipline - STM for biology or materials science or electrochemistry. In the corporate labs, postdocs, too, underwent a kind of training - in a position of constant oversight by colleagues and managers with the expertise and power to judge their work and affect their careers, corporate postdocs learned to build and use STMs geared specifically to institutional needs. Thus, corporate surface science STMs all looked relatively similar and were used

${ }^{20}<$ AG1 $>,<$ HG1 $>,<$ JN1 $>$. The propagation of a technique through the "cascade" of postdocs and collaborators away from one of the centers of an instrumental community is described in David Kaiser, Drawing Things Apart: The Dispersion of Feynman Diagrams in Postwar Physics (Chicago: University of Chicago Press, 2005). 
to look at the same handful of samples - though with enough variation to demonstrate their builders’ personal qualities of initiative, creativity, and experimental ingenuity. ${ }^{21}$

In other words, the instrumental community growing around the STM included elements of pedagogy at all participating sites, rather than just in the academic groups the STM was a technology for turning young researchers into full-fledged scientists as much as a new technique for characterizing materials. Analysts of academic capitalism should keep this in mind - universities have no monopoly on training in science, and the paths of pedagogy often seamlessly cross from the academic to the corporate world. Moreover, in this particular case the pedagogical uses of the STM encouraged a wider division of labor in the instrumental community. Because corporate postdocs were promoted based on their ability to integrate the STM with surface science, graduate students building STMs were instead encouraged to expand the instrument's capabilities into new areas. Corporations did, indeed, "influence” the direction of academic research here; but whereas many critics decry the constrictive, harmful effects of corporate influence, in this case corporate actors encouraged academics to adopt a diversity of approaches and an expansive outlook.

\section{Building and Buying}

In this sense, pedagogy drove the two moieties of early STM apart; yet in a variety of ways, corporate and academic participants were inseparable, particularly around practices of building microscopes and finding samples to characterize. Until 1986, all probe microscopes were "home-built" in that they were put together by the groups that were using them. Yet home-built instruments were not made entirely from scratch - some components were made by hand, but most were bought from commercial

\footnotetext{
${ }^{21}<$ BW2 $>$.
} 
suppliers. STM designs were strongly shaped by the commercial availability of components such as op amps and probe materials; but STM builders were also active consumers. They took commercial products and adapted them for unforeseen uses and negotiated with suppliers for equipment (vacuum chambers, piezoelectric crystals, video output devices, etc.) modified for their specific applications. ${ }^{22}$ Some suppliers, such as Burleigh (a piezoceramic maker in upstate New York) modified their products, using the advice of prominent STMers, so that they could sell the modified items specifically for the STM market. ${ }^{23}$ That is, professors were crucial both as consumers and producers. Most favorable analyses of academic capitalism have focused on academics as producers, with a view to stimulating professorial start-up companies; yet universities may find that the best way to gain a stake in an instrumental community is by encouraging professors to be smart, savvy, active consumers who have leverage with manufacturers both through their expertise and their potential for building their own product (or even starting a competing firm).

In a number of indirect and often counter-intuitive ways, commerce supplied the infrastructure of knowledge and standardization needed to make the STM community grow. Information about sources of reliable components and materials was a major topic of "gossip” among early STM builders. Those who had built working instruments recommended particular brands to new members of the community; and those

\footnotetext{
${ }^{22}$ Much recent history of technology has focused on the active role of users. For consumers' adaptations of artifacts for uses that manufacturers were unaware of, or even opposed, see Ronald Kline and Trevor Pinch, "Users as Agents of Technological Change: The Social Construction of the Automobile in the Rural United States,” Technology and Culture 37, no. October (1996): 763-95. For users' pressure on companies (often - as in instrumental communities - through threats to form their own cooperatives or firms), see Claude S. Fischer, America Calling: A Social History of the Telephone to 1940 (Berkeley: University of California Press, 1992). For an overview of different kinds of user activity, see the essays in Nelly Oudshoorn and Trevor Pinch, eds., How Users Matter: The Co-Construction of Users and Technologies (Cambridge, MA: MIT Press, 2003).

${ }^{23}<$ DF1 $>$.
} 
newcomers, anxious to make up for lost time, rarely questioned their predecessors' advice. Old-timers gladly gave newcomers blueprints and recommendations on suppliers, so that STM-building came to resemble doing a project from Popular Mechanics. Brands became an important carrier of the tacit knowledge of microscopebuilding, and STM-building became standardized through STMers’ nearly ritualistic allegiance to those brands, even when the technical rationale for the brand disappeared. For instance, IBM’s STMers used a trademarked rubber called Viton (from Dupont) to dampen vibration, because Viton could survive ultrahigh vacuum. ${ }^{24}$ Later, as IBM's blueprints disseminated, Viton became a hallmark of tunneling microscopy, even in academic STMs used in air or fluid, not vacuum. ${ }^{25}$

A commercial infrastructure also helped STMers standardize the materials they characterized. As Daniel Lee Kleinman has noted, this kind of corporate “influence” on research is pervasive but indirect. ${ }^{26}$ Yet tapping into the right commercial infrastructure can be crucial to growing an instrumental community and ensuring the credibility of its members' expertise - reliable, cheap commercial sources of materials give newcomers easy access to research, and give the rest of the community a yardstick by which to measure newcomers’ progress. Among corporate surface science STMers, this yardstick was provided by a few key metal and semiconductor samples on which newcomers had to prove their machines. When academic STMers designed microscopes for use in air and water, they needed alternative yardstick materials. Gold, paraffin, and graphite vied for

\footnotetext{
${ }^{24}<$ CG1 $>,<$ RT1 $>,<$ VE1 $>$.

${ }^{25}$ For similar instances of practices spreading through an experimental community through transmission of knowledge about particular brands, see Kathleen Jordan and Michael Lynch, "The dissemination, standardization, and routinization of a molecular biological technique," Social Studies of Science 28, no. 56 (1998): 773-800.

${ }^{26}$ Daniel Lee Kleinman, Impure Cultures: University Biology and the World of Commerce (Madison: University of Wisconsin Press, 2003).
} 
the job; but graphite won out partly because ultrapure samples could be obtained cheaply. ${ }^{27}$ Union Carbide used graphite to make monochromators for neutrons, an application requiring extraordinarily pure samples - hence, they rejected large amounts of slightly imperfect graphite still pure enough for STMers. The Quate group heard about this and alerted other academic groups who then called Union Carbide's graphite man, Arthur Moore, to get cheap, standardized samples. Soon, the STM community was awash in graphite, such that talks about that material finally outnumbered talks on semiconductors at the annual STM conferences.

Sometimes, the industrial relevance of materials was a more direct influence acting on academic microscopists, feeding back into the designs of their instruments. Yet the arrow of corporate-academic influence here was dramatically non-linear. Cal Quate, for instance, framed his STM work within Stanford's long tradition of industrial ties and his own involvement in developing acoustic microscopy in the '70s as a non-destructive characterization tool for manufacturing. ${ }^{28}$ Non-destructive testing held tremendous promise for microelectronics, where chips are inspected throughout manufacturing yet where traditional tools (especially electron microscopy) require breaking and discarding expensive silicon wafers. Quate moved into STM believing it could be the next generation non-destructive evaluation tool; and he was quickly followed by his former students and postdocs at IBM. ${ }^{29}$

\footnotetext{
$27<\mathrm{AG} 1>$.

${ }^{28}<$ JF1>, <DR1>, <MK1>. See C. F. Quate, “Acoustic Microscopy - Recollections,” IEEE Transactions On Sonics and Ultrasonics 32, no. 2 (1985): 132-135 for a brief description of scanning acoustic microscopy at Stanford.

${ }^{29}$ Quate's optimism for STM derived from its ultrahigh resolution and the fact that (ideally) the STM tip does not touch (and thereby mar) the sample surface.
} 
STM, though, requires a conducting (metal or semiconductor) sample, whereas most microelectronic materials have an insulating oxide layer. Indeed, controlled growth of oxides is crucial to turning silicon wafers into integrated circuits. This was unproblematic for corporate surface scientists tasked with generating basic knowledge about materials like silicon and gallium arsenide. Yet STM's restriction to conducting materials blocked its use in non-destructive testing and hindered movement into fields other than surface science. Those who wanted to carve interdisciplinary niches for STM saw its sample constraints as suffocating; chief among these were Gerd Binnig (an IBM employee but not a surface scientist) and Cal Quate (and his former students and postdocs at IBM). So when IBM allowed Binnig to take a sabbatical at Stanford in 1985-6, he and Quate pushed past the STM to invent the AFM - which, because it uses interatomic forces rather than tunneling to sense height, can map insulating materials. Thus, Quate positioned his research much further downstream in IBM's manufacturing cycle than most of IBM's own STMers and, together, IBM and Stanford dramatically shifted the world of academic and corporate probe microscopy.

\section{Commercialization and Gray Markets}

What we've seen so far, then, are the more intricate, unglamorous ways corporate and academic actors are linked within an instrumental community - through pedagogy, through institutional politics, through commercial infrastructures, through tacit knowledge. Most of relationships I've outlined thus far are not the ones that exercise proponents and critics of academic capitalism - large corporate buy-ins to academic departments, professors keeping research secret so they can patent it, corporations and universities colluding to suppress unfavorable results. 
One topic central to the academic capitalism debate will occupy the rest of this paper - the commercialization of academic research and the founding of professorial start-up companies. Yet I will show that commercialization only happens when it helps participants position themselves within an instrumental community; and that the commercialization process is not sudden and dramatic, but built slowly and quietly from the kinds of practices I have described thus far.

The proximate basis for commercialization of probe microscopy was the desire on the part of elite STMers to grow a larger community in which their groups would be centers of expertise. $^{30}$ This desire was strong among both corporate and academic groups, though the motivations differed in the two moieties. At IBM and (to a lesser extent) Bell Labs, research managers wanted to increase the number of in-house STM groups, so as to keep the center of the STM community within the corporation. Academics like Quate and Hansma wanted to grow the STM (and AFM) community because they were looking for new applications and audiences, and because they wanted to build a critical mass committed to non-surface science probe microscopy.

Thus, the stimulus to (a kind of) commercialization existed in both the corporate and academic environments, as did the practices and knowledge from which this protocommercialization could be constructed. Both Bell Labs and IBM, for instance, built something like an internal free market for tunneling microscopy, with multiple groups in different parts of the building set to work on very similar tasks and compete for the

\footnotetext{
${ }^{30}$ This analysis resonates with the early works of so-called actor-network theory: Michel Callon, "Some Elements of a Sociology of Translation: Domestication of the Scallops and the Fishermen of St. Brieuc Bay," in Power, Action, and Belief: A New Sociology of Knowledge, ed. John Law (London: Routledge, 1986), 196-233; Bruno Latour, Science in Action: How to Follow Scientists and Engineers through Society (Cambridge, MA: Harvard University Press, 1987); and Bruno Latour, The Pasteurization of France (Cambridge, MA: Harvard University Press, 1988).
} 
attention of senior managers. But both companies also developed an infrastructure for STM research that allowed groups to get up to speed very quickly. For instance, Bell Labs housed several (varying between two and four) STMs in an old tractor shed on the edge of its property; there, microscope builders could very quickly trade ideas, materials, blueprints, and software - very much in the same way that Quate's students worked on multiple microscopes at once and cannibalized parts from one project to another. ${ }^{31}$

IBM took the internal STM market/infrastructure to even greater lengths. IBM had been first into STM, yet it took other IBM groups just as long - almost two years in some cases - as everyone else to replicate the Zurich instrument. Thus, senior management cast about for ways to package the tacit knowledge of instrument-building and reduce replication time. The preferred strategy was to make semi-standardized, batch-produced STM packages available to its researchers. ${ }^{32}$ The first was the "Blue Box” designed by Othmar Marti, a Swiss graduate student doing doctoral work at IBM Zurich. $^{33}$ The Blue Box was primarily an electronics package - researchers constructed the hardware themselves, often using the Zurich team's designs. STM electronics presented a significant challenge - complicated feedback circuitry brings the probe to the surface, reads out and controls the tunnel current, and rasters the tip without crashing. Later, the success of the Blue Box in allowing newcomers to work around these difficulties inspired a more ambitious effort at IBM Yorktown. There, Joe Demuth, manager of an STM group, assigned his postdocs to work with Yorktown’s Central

\footnotetext{
${ }^{31}<\mathrm{JG} 3>$, $<\mathrm{BS} 1>$.

${ }^{32}$ See Philip Scranton, Endless Novelty: Specialty Production and American Industrialization, 1865-1925 (Princeton: Princeton University Press, 1997) for an analysis of batch-production.

$33<\mathrm{OM} 1>$, $<\mathrm{JG} 1>$.
} 
Scientific Services shop to develop and batch-produce complete STMs to "sell" to other Yorktowners. $^{34}$

By 1990, 10 to 20 of these CSS STM's were in use at Yorktown and the nearby Hawthorne facility; some also traveled to academic groups when postdocs left to become professors. ${ }^{35}$ Yorktown management encouraged use of the CSS STM by making its purchase a zero-cost budget item. Still, groups had to invest labor - usually a postdoc to make the microscope productive. This confronted its postdoc users with a dilemma. They needed to creatively solve technical problems and display initiative to managers to advance to staff positions; and advancement also required navigating competitive institutional politics, where groups worked in parallel on similar projects and were rewarded relative to each other. Postdocs using the CSS STM found they were viewed as partisans of Demuth's style of microscopy. To avoid alienating other factions at Yorktown, and display their own experimental prowess, they redesigned and rebuilt large parts of the CSS instrument. ${ }^{36}$ That is, the organization of Yorktown research kept the CSS microscope from turning into a widely-commercialized black box. ${ }^{37}$

${ }^{34}<$ BH1 $>$, $<$ RT1 $>$, $<$ JD2>.

${ }^{35}<$ DB1 $>$.

${ }^{36}<\mathrm{JV} 1>$, $<$ BW2 $>$.

${ }^{37}$ For the classic analysis of the instrument as "black box" (i.e., a technology that takes over epistemic responsibility from the experimenter by virtue of the inaccessibility of its workings), see Bruno Latour and Steve Woolgar, Laboratory Life: The Construction of Scientific Facts, 2 ed. (Princeton, NJ: Princeton University Press, 1986). My point here is that the "blackness" of the black box is continually reshaped in order to draw boundaries or form networks within an instrumental community. Commercialization can be a gradual process of making the black box less "translucent" and more less open to intervention; see Kathleen Jordan and Michael Lynch, "The Sociology of a Genetic Engineering Technique: Ritual and Rationality in the Performance of a "Plasmid Prep"," in The Right Tools for the Job: At Work in the Twentieth-Century Life Sciences, ed. Adele E. Clarke and Joan H. Fujimura (Princeton, NJ: Princeton University Press, 1992), 77-114. At the same time, the presentation of a commercial microscope architecture as "closed" (probe microscopists' term for a black box) or "open" (their term for translucent) is a political move designed to orient that microscope toward a particular market niche/subdisciplinary audience. See Cyrus C. M. Mody, "How Probe Microscopists Became Nanotechnologists," in Discovering the Nanoscale, ed. Davis Baird, Alfred Nordmann, and Joachim Schummer (Amsterdam: IOS Press, 2004), 119-133. 
The CSS STM was a kind of commercialization of tunneling microscopy, for the internal IBM market. Had Yorktown culture promoted formation of start-ups or collaborations with instrument manufacturers, the CSS microscope could have become the first mass-marketed STM. After the early '90s recession made IBM leaner and more outward-looking, Big Blue did market an AFM - Yorktown’s “SXM” - to the semiconductor industry. This exception, though, proves the rule. The SXM was invented by a former Quate postdoc, and owed much to Quate’s style of work. Yet commercialization was hindered by its IBM origins - though capable of astonishing resolution of the sidewalls of integrated circuit features, it was too finicky and unreliable (it needed a Ph.D. to operate) to attract an industry devoted to tools kept in continuous operation by relatively unskilled workers. ${ }^{38}$

In contrast, commercialization was more successful from academic STM and AFM groups largely because of the outward-looking, multidisciplinary style they had cultivated in order to avoid competing with the more insular and disciplined surface scientists at IBM and Bell Labs. People like Binnig, Rohrer, Quate, and Hansma were extraordinarily open with newcomers, freely offering them blueprints and advice in order to build a critical mass of non-surface science probe microscopists. Thus, the circulation of materials and ideas - a kind of "gray market" - became the norm in academic STM and AFM. ${ }^{39}$ Software, in particular, passed from group to group, and student cohort to cohort within research groups. Both academic and corporate groups wrote code that they gave to collaborators, strengthening their group’s position in the instrumental community,

\footnotetext{
$38<\mathrm{KW} 1>$, $<\mathrm{DB} 2>$, $<\mathrm{JG} 3>$.

${ }^{39}$ Davis Baird, "Scientific Instrument Making, Epistemology, and the Conflict between Gift and Commodity Economies,” Ludus Vitalis Supplement 2 (1997): 1-16.
} 
and ensuring access to collaborators' modifications to the code. ${ }^{40}$ Sometimes code was given for free, sometimes at nominal cost; profit was not the motive for dissemination.

The most well-traveled hardware innovation was the microfabricated AFM cantilever. One perceived defect of early AFMs was that probes were laboriously handmade from small strips of aluminum foil with a tiny sliver of diamond glued on one side and a tiny shard of glass on the other. ${ }^{41}$ Although these cantilevers could yield exquisite AFM images, each required considerable time and training, and results were so particular to one cantilever and its maker that images taken with different cantilevers were difficult to compare. Hand-made cantilevers sufficed early on, when every image was new and spectacular; but as the technique matured, AFMers sought standardization. The Quate group delivered this by integrating itself with microlithography expertise at Stanford and around Silicon Valley. Over several years, Quate shared students with other electrical engineering professors at Stanford, allowing them to learn AFM before going to the clean rooms to learn to pattern and etch silicon into small, standardized batches of cantilevers. By 1990, Quate began sending surplus probes to friends and collaborators, sometimes so he and his students could share authorship of collaborators’ papers. Quickly, Quate-type probes became essential to the AFM infrastructure. ${ }^{42}$

At the same time, Quate and Hansma prepared the ground for commercialization through their practice of bringing in collaborators from a variety of disciplines. On the one hand, these collaborators would found their own STM or AFM groups and

\footnotetext{
$40<$ MS1>

${ }^{41}$ Diamonds were used as tips because their sharp points were less likely to wear down from repeated use than other materials. The glass on the back of the cantilever acted as a small mirror, bouncing laser light into a photodiode; the position of the reflected beam in the photodiode indicated how much the cantilever was bending (i.e., a proxy for how much the surface was pulling or pushing on the diamond tip).

$42<$ TA1>, <MK1>, <BD2>.
} 
effectively "advertise" for the technique, building interest - what would become markets - in probe microscopy among biologists, electrochemists, mineralogists, and so forth. On the other hand, within the Quate and Hansma groups graduate students learned the art of dealing with potential “customers” from other disciplines and designing microscopes with their needs in mind. The leap from these practices to outright commercialization was very small.

In the end, the first to make this leap was a Quate student, Doug Smith, who founded the Tunneling Microscope Company in 1986. Notably, though, there was wariness about this commercialization on both the supply and demand sides. Smith had only one "employee", a fellow student who helped put together scanners, and he recruited customers by word of mouth. He viewed the company less as an ongoing enterprise than as a way to sweeten the hardships of graduate school - a well-circulated story is that he sold just enough microscopes to buy a BMW before taking a postdoc. Yet despite the small size of this venture, Quate himself was ambivalent and pushed Smith to separate scholarship and business more cleanly - "Dr. Quate said 'graduate students work, eat, and sleep, and most of the time they go hungry.' You can't have a company and be a graduate student at the same time, so Doug had to finish up and move out”. ${ }^{43}$

On the demand side, Smith's customers were in much the same position as the postdocs at IBM who were presented with the Blue Box or CSS STM. They saw a commercial STM as a way to quickly catch up and join a hot new instrumental community; yet they knew that if they were to join the elite of that community, they would have to demonstrate instrument-building virtuosity, and gear their STM to specific, arcane applications. Thus, like the batch-produced IBM instruments, Smith’s

${ }^{43}<\mathrm{MK} 1>$. 
commercial STMs were more starter kits than black-boxed devices. To use the instrument, customers needed to construct much of it on their own. ${ }^{44}$ All Smith sold was the microscope "head" - the piezoelectric scanner, tip, base, and vibration-isolating stacks of Viton. Customers built the electronics themselves, customizing the microscope for their own applications.

In debates about academic capitalism, the commodification of academic expertise is usually treated as an undifferentiated matter, as are the consumers of that expertise. Yet it should be clear from the STM and AFM story that the symbolic elements of the “product” sold by members of an instrumental community is crucial and ever-changing. Today, when customers by an off-the-shelf AFM, they generally are buying all of the expertise of microscope-building so that they won't have to develop it themselves. Early on that expertise was exactly what customers of commercial STMs did not want to buy; instead, they were purchasing time and membership in a community and the opportunity to develop their own instrument-building expertise. Consumers wanted to be on an equal footing with producers, whether in a commercial or academic setting. Thus, there was no “academic ethos” that was corrupted by these early ventures into batch production; yet neither was there a "corporate ethos" demanding that firms make money from the STMs their employees had built. Rather, in both settings it was the culture of the instrumental community that shaped the meanings (and timetable) of commercialization.

\section{Digital Instruments}

Commercialization of the STM, then, was a process accomplished through a series of minute, unremarkable steps - very little separated the home-built STM, made with parts ordered from catalogs, often using blueprints given by colleagues, from the

\footnotetext{
${ }^{44}<\mathrm{JF} 1>,<\mathrm{NB} 1>,<\mathrm{RC} 1>$.
} 
STMs sold by Smith and (internally) IBM. The next step was only slightly more dramatic - the founding of organizations dedicated wholly to manufacturing and selling probe microscopes. Critics and proponents of academic capitalism both lay heavy emphasis on the founding of start-ups; it is seen both as the best means to extract profit from academic work, and as the ultimate distraction from the university's pedagogical mission. Yet both these views neglect the realities of how start-ups operate within an instrumental community. Profit is often the least visible (and least successful) motivation for founding a start-up; and start-ups often continue and enhance the pedagogical culture of an instrumental community rather than despoiling it.

Digital Instruments, the first true start-up in the probe microscopy community, offers vivid illustration that the most successful start-ups may be those that build outward from an instrumental community's gray markets and culture of circulating people, ideas, and materials, rather than bringing a management-driven, profit-focused ideology into that community. DI was the brainchild of Virgil Elings, one of Paul Hansma's colleagues in the physics department at UC Santa Barbara. Elings first contact with the STM community, though, was Niko Garcia, a visiting Spanish academic with close ties to IBM Zurich. After talking with Garcia and Hansma and attending the 1986 STM Conference in Spain, Elings saw a market for an off-the-shelf STM and offered to co-found a company with Hansma. Hansma was even more wary than Quate of commerce encroaching on his lab's activities, so he declined; but he gave Elings the same advice and schematics he made available to other STMers. ${ }^{45}$ With this, Elings and his son built

$45<$ PH1 $>$, <VE1>. 
a prototype in their garage and entered it in a junior high science fair (where it took last place, since, as the judges pointed out, “everybody knows you can’t see atoms”). ${ }^{46}$

For Elings, building the prototype was a chance to make sure the Hansma design was commercializable, but also to test - and discard - many axioms of STM-building that accrued since 1981. Elings saw STM builders' trade secrets as geared to instruments that were finicky and difficult to operate; and he saw possession of these trade secrets as limiting the STM community to those deemed "serious" enough to build their own microscopes. Elings wanted, eventually, to make STMs specifically for non-builders who demanded a simple-to-operate black box. Thus, he delighted in “debunking” the STM-builders’ recipes by creating a more streamlined, easy-to-use, more durable tool.

Elings wanted DI to be the first to market a commercial microscope by the annual STM Conference in 1987. Though his plan was always to sell a computer-controlled microscope (hence Digital Instruments), his former student (and DI co-founder), Gus Gurley, was brought in too late to finish all the code in time. Instead, Elings marketed the analog Nanoscope I as DI’s first product. Probe microscopists from this era - both builders and buyers - remember their first acquaintance with the Nanoscope as a turning point. Now, for the first time, researchers could join the STM community without having to build any part of their microscope. Moreover, unlike Smith’s clients, DI’s customers didn’t need to have personal ties to the community; people could (and did) simply call up Digital Instruments and order a microscope.

Yet though it marked an important shift, the Nanoscope I still illustrates the gradual, emergent character of commercialization. Digital retained much of the flavor of a lab like Quate’s or Hansma’s; and Elings only slowly came to sell a more and more

\footnotetext{
${ }^{46}<$ MT1 $>,<$ VE1 $>$.
} 
complete microscope, to rely less and less on customers' design expertise, and to view money as the primary token of exchange. Like the CSS STM and Doug Smith’s instrument, the Nanoscope I was more a kit than a full-fledged, black-boxed research tool. Indeed, Elings now calls this era at DI the "toy business" - both for the Nanoscope I's immature design, and for its lack of "serious" applications. ${ }^{47}$ In following Hansma's lead, Elings designed an air STM, rather than the expensive, narrow-niche ultrahigh vacuum instruments used at IBM and Bell Labs. This made sense in opening up a broad market, since few disciplines were willing to deal with or pay for ultrahigh vacuum (which, in any case, ruined samples relevant to everyone except surface scientists). Yet it was unclear in the '80s what air STM could be used for, or what the images it produced meant. Only in 1991-2 did a consensus develop that air STM was not, in fact, relying on tunneling for its contrast mechanism, and that many well-publicized air STM images (particularly of DNA) were erroneous. As a result, most air STMers abandoned the technique and followed Quate and Hansma to AFM, usually by buying one of DI's newly-available "Multimodes” (capable of running both STM and AFM).

Thus, the Nanoscope I and other air STMs had little rigorous application, though until 1992 it seemed possible such applications would appear if researchers could buy cheap commercial STMs and adapt them for unforeseen purposes. The Nanoscope I was a 'toy' because it was meant to be superseded, and because its buyers were envisioned as instrument-savvy and willing to experiment playfully with their new device until promising applications were found (not unlike DI’s engineers themselves). This assumption of similarity between designers and users allowed new designs and applications to flow in from the market and inform production of the more black-boxed,

${ }^{47}<$ DC1 $>$, <VE1>. 
all-digital Nanoscope II. Hence innovation came rapidly because participants in the probe-microscopy field comprised an experienced and critical body. In fact, researchers who had previously built their own STMs formed a small but elite group of DI's early customers.

The assumed similarities of DI's engineers and early customers also reinforced its self-image as a freewheeling startup that could rely on its users to make up for its lack of marketing and customer service. Elings had no sales force - he simply advertised in Physics Today - (“\$25,000 for atomic resolution”) and orders came in. Instruments were FedExed to buyers, who put them together and got the microscope running on their own. Despite this minimal marketing and customer service (and limited product utility), the toy business was successful. An advertisement from 1990 estimates that in the first three years, DI sold more than 300 Nanoscopes at $\$ 25,000$ to $\$ 35,000$ each. ${ }^{48}$ The probe microscopy community expanded quickly, and the center of gravity shifted as well; as more people bought instruments, AFM and air STM began to outweigh UHV STM, and the corporate labs became less dominant. High demand created a waiting list, prompting a policy that researchers who wanted a microscope quickly could promise to name DI’s founders or employees as co-authors on papers generated with Digital's products.

DI recognized that to create a market among scientists and engineers, it had to demonstrate its trustworthiness as a producer both of microscopes and of knowledge. ${ }^{49}$ Through its customers, DI associated credible facts with its instrument and its employees, enticing consumers of those facts to join the probe microscopy community by becoming

\footnotetext{
${ }^{48}$ From FASEB Journal, v.4, n. 13 (1990), p. 1.

${ }^{49}$ This analysis draws on Latour and Woolgar's concept of the "cycle of credit", but from the perspective of the instrument seller, rather than the buyer. Bruno Latour and Steve Woolgar, Laboratory Life: The Construction of Scientific Facts, 2 ed. (Princeton, NJ: Princeton University Press, 1986).
} 
consumers of its products. Notably, because the community still largely operated on a gray market, Digital had to rely heavily on barter - such as trading waiting list position for authorship. Such trades gradually diminished as the probe microscopy community became more commercial; indeed, “commercialization” often signifies the narrowing of the varieties of exchange as a technology stabilizes, rather than the encroachment of a peculiarly corporate ethic into the academy. ${ }^{50}$

\section{The Start-Up Era}

The end of the toy business roughly corresponded to the end of DI's solitude in commercial probe microscopy. By 1990, the probe microscopy community was growing dramatically, fueled by (and fueling) the appearance of a rash of new STM and AFM manufacturers. Their products and strategies differed considerably - some competed with Digital Instruments for the general-purpose microscope market, some targeted specific disciplinary niches, some made easy-to-operate black boxes, some built “open architectures” for researchers who wanted to tinker with and modify the device. Some survived, others floundered. All were small companies, mostly founded out of universities specifically to make probe microscopes, though a few drifted to that product line. No big firms made more than desultory attempts to sell STMs or AFMs - though a few (Hitachi, IBM, Perkin Elmer) started down that road.

Crucially, these start-ups were founded for a deliciously diverse set of reasons. Most debates about academic capitalism simply assume that, under the current set of

\footnotetext{
50 There is a complicated relationship between "commercialization” and "stabilization” of a technology; for analyses of stabilization, see Wiebe E. Bijker, Of Bicycles, Bakelite, and Bulbs: Toward a Theory of Sociotechnical Change, ed. Wiebe E. Bijker, Trevor Pinch, and Geof Bowker, Inside Technology (Cambridge, MA: Massachusetts Institute of Technology Press, 1995) and Paul Rosen, "The Social Construction of Mountain Bikes: Technology and Postmodernity in the Cycle Industry,” Social Studies of Science 23 (1993): 479-513.
} 
incentives and stimuli, professorial start-ups are an inevitability - for good or ill, the inducements for professors to commercialize their work is simply irresistible. Maybe so, but this assumption looks less reliable when the contingent and often counter-intuitive reasons why people found start-ups are examined. Digital Instruments provides a striking example. DI and Elings thrived at UCSB's disreputable margins. When he arrived in the late '60s as a brash, confrontational professor, it was hoped Elings would build UCSB's reputation in high energy physics. His swagger, though, led to conflict with his department, which sidelined him into running their less prestigious Master's of Scientific Instrumentation program - a lucrative but unloved backwater. ${ }^{51}$ Uncowed, Elings transformed the master's program into his personal empire and a fountainhead for patents and start-up companies.

In the master's program students from many educational backgrounds (biologists, engineers, even psychology majors) learned to build all kinds of measurement technologies - not just research instruments but also industrially-relevant meters and tools. Initially, Elings relied on orthodox classroom instruction; but soon, he drifted toward an alternative method that prized tacit over formal knowledge, participation over instruction. Instead of textbooks and lectures, he simply connected students with professors on campus who needed instruments built and let them learn by doing. Because student projects were based on finding solutions to real problems faced by local researchers, they often yielded technologies Elings could market to those researchers' subdisciplines. Students learned how to understand customers' needs and design technologies to answer them. This made former master's students the most important source of early employees for all Elings' ventures, especially Digital Instruments.

${ }^{51}<$ JW1>. 
So UC Santa Barbara did, in a way, encourage creation of DI, though no school would replicate their path. By sidelining a brilliant but difficult professor to the poorlyregarded master's program, they encouraged him to reject campus culture, denigrate academically-instilled formal knowledge, and be receptive to the commercial possibilities of the tacit knowledge his students accrued. Moreover, in making clear Elings’ commercial ventures hindered his academic career, the UCSB physicists made it more likely his next enterprise - Digital Instruments - would be his bridge to leaving academia. Tension between Elings and UCSB even smoothed technology transfer from Hansma to DI, since Elings' hostility toward academic researchers meant he rejected Hansma's designs until they had been engineered to look more like commercial products than most home-built instruments.

Disgruntlement of a different kind also fueled both DI and some of its competitors. Several of the early STM and AFM manufacturers were founded in the heart of the West Coast military-industrial complex. Graduate students who had grown accustomed to the picturesque surroundings and lifestyle of southern California often sought employment nearby - usually with defense firms like Lockheed and Hughes. Yet defense work galled many of these engineers, driving them back to probe microscopy. Much of Elings' early work-force came to DI for this reason; and in Los Angeles Paul West, one of John Baldeschwieler's former postdocs at Caltech, grew so frustrated with defense work that he started his own probe microscopy company, Quanscan.

In several cases, start-ups positioned themselves relative to each other in ways that mirrored the relationships between the academic groups with which they were associated. Digital Instruments may not have been officially affiliated with the Hansma 
group at first (indeed, even at the best of times, there was always some suspicion between the two groups), and Elings was certainly proud of the ways the Nanoscope differed from Hansma's microscopes; but DI’s products bore an obvious genealogical kinship with Hansma's STMs and AFMs, and DI drew on Hansma's reputation in the community. In return, Hansma's design innovations spread much farther and faster than those of professors not affiliated with a start-up. Thus, Hansma's peers in the probe microscopy elite were more enthusiastic than he about helping former personnel found start-ups. For instance, two Stanford postdocs, Sung-Il Park and Sang-Il Park (no relations) started Park Scientific Instruments in 1989 with Quate's help and quickly became the major employer of Quate group veterans; PSI's designs, even more than DI's, were ported straight from the academic group, and the research in new applications conducted there often picked up where Quate's own research left off. ${ }^{52}$ Commercialization is the politics of academic research by other means.

Similarly, just as Baldeschwieler’s groups always lagged behind Quate’s and Hansma's in popularizing its discoveries and innovations, the company he helped Paul West found, Quanscan, lagged behind DI and Park Scientific in marketing commercialized versions of the Caltech designs. As Bourdieu might put it, relations defined by intellectual capital in the academic field mapped onto relations of commercial capital in the start-up field. ${ }^{53}$ These relations could sometimes be based on collaboration as much as competition. For instance, Stuart Lindsay, a physics professor at Arizona State University, had been an early collaborator of Hansma's, one of the first in the long series of visitors to UCSB who helped adapt the STM to new applications and

\footnotetext{
${ }^{52}<\mathrm{DB} 3>$, $<$ FG1 $>$, $<\mathrm{JN} 1>$.

${ }^{53}$ Pierre Bourdieu, “The Forms of Capital," in John Richardson, ed., Handbook of Theory and Research for the Sociology of Education (New York: Greenwood Press, 1986), 241-258.
} 
subdisciplines - in Lindsay’s case, for electrochemistry and for biological materials. Once Hansma’s designed were commercialized by DI, Lindsay pressed Elings to adapt the Nanoscope for Lindsay's colleagues in electrochemistry and biophysics - to no avail, since Elings was usually hostile to adapting the Nanoscope for anyone (DI had a strict no-custom-instruments policy), especially when the suggestion came from outside the company. So Lindsay founded his own company, Molecular Imaging, to make attachments to the Nanoscope that would make it more compatible with electrochemistry and biophysics - attachments which DI grudgingly distributed for a few years until it developed its own competing line. ${ }^{54}$

Lindsay's other motivations for founding a start-up say a great deal about how commercialization and pedagogy fit together in instrumental communities. Long before Molecular Imaging, his group - like Hansma's at UCSB - had become a center for distributing blueprints and (especially) software to new STM builders. One of Lindsay's technicians, Uwe Knipping, developed one of the first and most sophisticated computercontrolled microscopes; Knipping's software formed the basis for Lindsay's academic network-building, but it also caught the eye of two local entrepreneurs, Larry and Darryl McCormick, who founded a company, Angstrom Technology, to commercialize it. ${ }^{55}$

As it turned out, Knipping's architecture was far too sophisticated for a commercial instrument, and the enterprise failed. But Lindsay had gotten a taste for how network-building in the academic domain might be enhanced by commercialization. So a few years later when he happened on a former postdoc who was having trouble finding work, Lindsay decided to built a new company - Molecular Imaging - around him as an

\footnotetext{
${ }^{54}<$ SL1 $>$.

${ }^{55}<$ SL1>, <JA1>.
} 
extension of the work going on at ASU. ${ }^{56}$ This is probably the classic - if woefully understudied - story of commercialization: a professor's technicians and graduate students make a widget, then the professor's colleagues call up asking for their own widget (or blueprints thereof), a student start making batches of widgets in their garage, and eventually - whether to help position the professor within that instrumental community or to give lab personnel needed work - the widget-making is spun off as its own kind of organization. Commercialization here makes the academic research more streamlined and focused by being an extra bin in which to throw specific kinds of muchneeded people and community-building work.

In only a few cases were probe microscope start-ups inspired by the incentives to commercialize and culture of entrepreneurialism so central to the debate about academic capitalism. Paul West, for one, explicitly saw entrepreneurship as a challenge and path to personal growth, and the Baldeschwieler group had a long history of spinning off commercial enterprises. ${ }^{57}$ Similarly (but to a much lesser extent) the Parks and their employees molded PSI in the image of Stanford's tradition of commercialization, and Quate's particular tradition of sending former students to the most powerful firms in Silicon Valley. Yet these start-ups' success was seemingly in inverse proportion to the entrepreneurial intent of their founding. Quanscan (and its successor company, Topometrix) was always the most business-like - had the most venture capital money, the most MBAs, the slickest advertising, etc. But these proved a drag on the company's fortunes - the bankers continually interfered in operations, the MBAs had trouble

\footnotetext{
${ }^{56}<$ SL1 $>,<$ TJ1 $>$.

${ }^{57}<$ PW2 $>,<$ JB1 $>,<$ GA1 $>$.
} 
understanding the values of an instrumental community that they had never participated in, and the advertising alienated many potential customers.

Park Scientific, like DI, was a more rough-hewn affair - Sung-Il Park’s barber was hired as the office manager, for instance, and the senior management were Quate students with no business training. ${ }^{58}$ Indeed, the Parks carved a niche for their instruments by cultivating an image of themselves as interested much more in technically sweet innovations than in mundane moneymaking. As "gentleman scientists," they could speak as peers with other researchers and capture customers' trust. Park Scientific gained a reputation for making "builders'” instruments - well-crafted, reliable, with enough idiosyncracies and innards showing to be reminiscent of a microscope made by a graduate student. Park was even willing to work with individual customers to build a microscope for a specific application (something DI never did) - if the engineering required a certain finesse. Yet ultimately this sapped the company. Park rode to some success on the same hostility to management expertise as DI; but Digital ultimately won out because (once the toy business was over) it displayed an almost equal hostility to the expertise of its customers. Where Park was willing to relive the days of the Quate lab by respecting the knowledge of foreign disciplines, DI made one type of microscope for everyone, and hid the workings of that instrument completely from customers' view. This attitude allowed DI to break into the industrial market, where it could sell radically more, and more expensive, microscopes to companies that usually wanted low-level technicians to learn how to use the instrument in a day or two - market conditions for which Park was wholly unprepared.

${ }^{58}<\mathrm{DB} 1>$, <BP1>. 
As much as DI eventually prospered by distancing itself from Hansma’s academic model, though, the company's success hinged equally on continual borrowings of culture, people, and inventions between start-up and academic lab. By chance, these borrowings were facilitated by Elings and Hansma’s convergence on similar pedagogical philosophies. Both me saw tacit, rather than formal, knowledge as primary in instrumentbuilding - Elings because of his work in the instrumentation master's program, Hansma because the contours of the STM community had pushed him to encourage undisciplined instrument-building rather than disciplined instrument-use. This shared emphasis on the tacit meant both men took in people with diverse and unusual educational backgrounds: junior high students, river guides, undergraduates, yoga instructors, retirees, psychology majors, and historians. ${ }^{59}$ This diversity was unthinkable at other centers of probe microscopy. Orienting to tacit knowledge also meant both DI and the Hansma group thrived on self-cultivating activities seemingly unrelated to technical matters; Hansma’s group found technical inspiration in pastimes such as woodworking, meditation, photography, yoga, river-rafting, etc; while DI held weekly “inventing sessions” where employees brainstormed solutions to esoteric (i.e. non-AFM-relevant) technical questions (e.g. "how do you make a self-balancing laundry machine”) to become better inventors and hone their skills at weathering Elings' intense skepticism. ${ }^{60}$

As members of DI and the Hansma group became aware of parallels between their organizational styles, they appropriated these similarities to accelerate the two-way flow of people, materials, designs, and knowledge. After the initial phase (when most DI employees were Elings’ former master’s students), several Hansma graduates, postdocs,

\footnotetext{
$59<\mathrm{HH} 1>$, $<\mathrm{JM} 3>$, $<\mathrm{DB} 2>,<\mathrm{MT} 1>,<\mathrm{BD} 2>$, $<\mathrm{PH} 1>$.

$60<$ JH1 $>$, $<$ DB2 $>$, $<$ PM1 $>$.
} 
and collaborators took high-ranking jobs at Digital. Individuals on both sides collaborated to transform Hansma's research into commercial products; for instance, the Hansma AFM (on which DI's fortunes eventually rested) was turned into a product through negotiations between Barney Drake (Hansma’s technician) and James Massie (a former Elings student) over which elements of the Hansma design were indispensable and which were too finicky for anyone but the graduate students who built them. ${ }^{61}$ As DI's sales increased, the Hansma group kept its place at the forefront of the AFM community through its steady supply of DI instruments and the ability of Hansma's students and postdocs to go up the road to DI to scavenge parts and advice. ${ }^{62}$ That is, whatever his initial reservations about commercialization, Hansma came to see the partnership with DI as a way to position himself - intellectually and socially - within his instrumental community.

In turn, once the "toy business" ended in the early ' 90 s, Elings began to imitate Hansma's tactic of bringing in postdocs to guide instrument-builders' efforts. DI built its own group of researchers from biophysics, magnetics, and polymer chemistry, who (like Hansma's postdocs) worked with instrument-builders, developed and published on new STM and AFM applications, and traveled to give talks and attend conferences to spread word about the technique. ${ }^{63}$ Though DI was a profit-making venture, its success arose partly from the Hansma group practices that it mirrored - doing research, publishing articles, training and "graduating” employees. These practices were then widely emulated by the other start-ups.

\footnotetext{
${ }^{61}<\mathrm{BD} 2>$, $<$ JM3 $>$.

$62<\mathrm{JH} 1>$.

${ }^{63}<$ SM2>, $<$ MA1 $>$.
} 
This kind of cultural/organizational parallelism from university to start-up is welldocumented in other fields of commercialization, especially biotechnology; there, it was used to entice professors to exit the ivory tower, leading to trouble when professorentrepreneurs were reluctant to turn their companies from research to profit-making. With STM and AFM, in contrast, corporate-academic isomorphism was successful less as a deliberate strategy than as a contingent and emergent harmonization of practices. It was a largely accidental outcome of the organization of this instrumental community that Quate, Hansma, and other academics promoted a gray market of circulating people, practices, and technologies that fostered successful commercialization.

\section{Conclusion}

So what does probe microscopy tell us about commercialization of academic knowledge and the value of corporate-academic linkages? First, the development of probe microscopy shows how thoroughly - yet intricately and indirectly - the corporate and academic worlds are connected. The locus of 'academic research' is much wider than the university campus, just as the locus of 'commerce' is wider than the for-profit business. Instrumental communities and other informal organizations are distributed across academic and corporate institutions. Commercialization - the transformation of academic research into commerce - is not a simple pipeline from university to firm. Commercialization can play many roles within an instrumental community, and academic research can be traded for many things other than money. Attempts, therefore, to directly stimulate and accelerate the transformation of academic research into cash may well backfire. As we have seen, it was the looser, indirect ties between corporate and academic groups that fostered the growth of STM and AFM and encouraged startups to 
emerge from universities, rather than direct pressure from corporations or overt incentives from governments and universities.

Thus, proponents of academic entrepreneurialism should be wary of focusing too narrowly on increased profit as the fruit of a commercialized university. As we've seen, trading goes on all the time in instrumental communities; the token of exchange is usually a mix of knowledge, prestige, personnel, time, materials, money, opportunity, etc. The popularity of various forms of barter changes as the instrumental community changes; commercialization can restrict some exchanges and make money-based trades more prevalent. Few instrumental communities reach this point, though. Even within the probe microscopy community, only the atomic force microscope and the magnetic force microscope have been commercial successes; the STM, which provided the first product for microscope manufacturers, was effective in training engineers to build microscopes, but never found industrial application. The presence of gray markets in instrumentation can enhance national economic growth over time; yet university administrators who hope that this or that gray market can be converted into a profit-making start-up to enhance local, short-term economic growth will almost always be disappointed.

Moreover, development of an entrepreneurial instrumental community may require that its members be drafted from less profitable fields where commercialization did not occur. The STM and AFM community, for instance, initially drew on its members' expertise in low-energy electron diffraction, sandwich tunnel junction spectroscopy, and field ion microscopy - instrumental communities with poor records of commercialization; later, STM and AFM pulled in participants from many fields (surface science, biophysics, mineralogy, electrochemistry, polymer science - some more 
commercialized than others) who aided groups like Quate’s and Hansma’s in their gray market activities. Instrumental communities in which the cultural map is unconducive to profit-making nevertheless provide the infrastructure and knowledge/labor pool for communities in which profit may be enormous. Policy-makers should not think they can predict which will be which; nor are they likely to succeed if they encourage only the one at the expense of the other. Policy makers may be best advised to encourage professors to foster gray markets within their instrumental communities - whether as consumers, producers, or both. Gray market activities of trading research materials, people, and components of technologies enlarge the outlook of academic research. By focusing on the wider instrumental community surrounding a technology, we can see that the university may actually be more influential in maintaining a pool of skeptical, independent consumers who can threaten start-ups with the prospect of making their own tools or even founding their own firms.

Finally, both opponents and supporters of corporate involvement in university life have seized on grains of truth. Supporters have it right that corporate-academic linkages are desirable, even necessary, for research and innovation. There was no golden age when faculty operated independent of firms, pursuing disinterested research; knowledge production in physics, engineering, and chemistry was always aided by faculty consulting and trading of personnel and ideas. The oft-criticized commercialism of the "biotech revolution” merely extended long-standing entrepreneurial practices into molecular biology. The STM and AFM case does, however, give reason for opposing the notion that universities should be run as businesses, squeezing profit where they can and operating along the "rational" lines of modern management. The probe microscopy 
community developed rapidly because participants could point to different institutional poles - corporations, universities, national labs. At times, innovation occurred because these poles were opposed - as when Hansma and Quate shifted from surface science and UHV STM to new designs and applications. At other times, innovation occurred because participants strung out hybrid forms between these poles - the gray market of software trading, the CSS STM, and the "toy business". Instrumental communities rely on a variety of actors, contained in different kinds of institutions. If all these institutions are run on the same highly-managed, profit-driven model, then the movement of people and ideas, and the production of new technologies, will likely be hindered.

\section{Appendix}

Interviewees listed by alphanumeric, name, positions held over the period covered by the interview, and date of the interview. All interviews conducted by the author.

AG1: Andy Gewirth: Hansma collaborator; University of Illinois; 6/26/01

BD2: Barney Drake: Hansma group technician; UCSB; 10/18/01

BH1: Bob Hamers: Yorktown researcher; University of Wisconsin; 5/9/01

BP1: Becky Pinto: Stanford; Park Scientific; KLA-Tencor; 2/3/04

BS1: Brian Swartzentruber: Bell Labs technician; University of Wisconsin; Sandia

National Laboratory; $1 / 10 / 03$

BW2: Bob Wolkow: IBM Yorktown; Bell Labs; NRC Canada; 5/22/01

CG1: Christoph Gerber: IBM Zurich technician; 11/12/01

CP1: Craig Prater: Hansma graduate student; Digital Instruments engineer; 3/19/01

DB1: Dawn Bonnell: Yorktown postdoc; University of Pennsylvania; 2/26/01

DB2: Dan Bocek: UCSB undergraduate; DI engineer; Asylum Research; 3/23/01

DB3: David Braunstein: Stanford; Park Scientific; IBM San Jose; 4/3/01

DC1: Don Chernoff: Sohio Research; Advanced Surface Microscopy; 9/5/01

DF1: Dave Farrell: Burleigh Instruments; 5/29/01

DR1: Dan Rugar: Quate student; Almaden researcher; 3/14/01

FG1: Franz Giessibl: IBM Munich; Park Scientific; Uni Augsburg; 11/16/01

GA1: Gary Aden: Topometrix executive; 3/12/01

HG1: Hermann Gaub: Ludwig-Maximilians Universität; 11/14/01 
HH1: Helen Hansma: UCSB professor; 3/19/01

JA1: John Alexander: Angstrom Technology; Park Scientific; KLA-Tencor; 10/15/01

JB1: John Baldeschwieler: Caltech; 3/28/01

JC2: Jason Cleveland: Hansma student; Digital Instruments; Asylum Research; 3/20/01

JD2: Joe Demuth: Yorktown manager; 2/22/01

JF1: John Foster: Quate student; Almaden researcher; 10/19/01

JG1: Jim Gimzewski: IBM Zurich researcher; UCLA; 10/22/01

JG3: Joe Griffith: Bell Labs; 2/28/01

JH1: Jan Hoh: Hansma postdoc; Johns Hopkins; 6/10/02

JM1: John Mamin: UC Berkeley; IBM Almaden; 3/15/01

JM3: James Massie: Elings master's student; DI engineer; 10/18/01

JN1: Jun Nogami: Quate postdoc; Michigan State; 6/28/01

JV1: John Villarrubia: Yorktown postdoc; National Institute of Standards and

Technology; 6/28/00

JW1: Jerome Wiedmann: Elings master's student; DI employee; 10/18/01

KW1: Kumar Wickramasinghe: Stanford; IBM Yorktown; 2/23/01

MA1: Mike Allen: UC Davis; Digital Instruments; Biometrology; 10/12/01

MK1: Mike Kirk: Quate student; Park Scientific Instruments; KLA-Tencor; 10/12/01

MS1: Miquel Salmeron: Lawrence Berkeley National Laboratory; 3/9/01

MT1: Matt Thompson: Digital Instruments; 2/26/01

NB1: Nancy Burnham: Naval Research Lab postdoc; Worcester Polytechnic; 2/20/01

OM1: Othmar Marti: IBM Zurich student; Hansma postdoc; University of Ulm; 11/16/01

PH1: Paul Hansma: UC Santa Barbara; 3/19/01

PM1: Pete Maivald: DI employee; 10/18/01

PW2: Paul West: Caltech; Quanscan; Topometrix; Thermomicroscopes; 3/30/01

RC1: Rich Colton: Naval Research Lab; Baldeschwieler collaborator; 6/27/02

RT1: Ruud Tromp: Yorktown researcher; 2/23/01

SG1: Scot Gould: Hansma student; DI employee; Claremont McKenna; 3/27/01

SL1: Stuart Lindsay: Hansma collaborator; Arizona State; Molecular Imaging; 1/6/03

SM2: Sergei Magonov: Digital Instruments; 3/21/01

TA1: Tom Albrecht: Quate student; Almaden researcher; 3/14/01

TB1: Thomas Berghaus: Uni Bochum; Omicron; 11/19/01

TJ1: Tianwei Jing: Arizona State; Molecular Imaging; 1/7/03

VE1: Virgil Elings: UC Santa Barbara; Digital Instruments; 3/20/01 